\title{
Investigating the Use of Online Learning Resources by the EAP Students in a UK University
}

\author{
Serpil Meri Yilan \\ School of Foreign Languages, Agri Ibrahim Cecen University, Agri 04100, Turkey
}

\begin{abstract}
This study was undertaken to examine English for Academic Purposes (EAP) students' perceptions and use of online learning resources (OLR), which are freely and openly available digital materials. The study utilized both quantitative and qualitative research instruments to collect data. EAP students who came to the UK to improve their language and then wished to undertake a postgraduate study there completed pre- and post-questionnaires during the first academic semester. They also replied to semi-structured interview questions after each questionnaire. The findings gave insights into both the students' awareness to use OLR outside the classroom, and the students' exercise of learner autonomy through scaffolding from OLR. However, they seemed still dependent on their teacher. The reason of this dependence might be the challenges they faced whilst learning. This study made some recommendations for the design of a scaffolded autonomous e-learning environment in order to benefit from OLR.
\end{abstract}

Keywords: online learning resources, English for academic purposes, e-learning, scaffolding, learner autonomy DOI: $10.7176 / \mathrm{JEP} / 10-15-14$

Publication date:May $31^{\text {st }} 2019$

\section{Introduction}

The integration of technology into learning has changed the way to learn English. Not just primary and secondary schools but also higher education institutions have increased to provide online learning resources (OLR) in a designed e-learning environment where students are offered to use computers and laptops (e.g. Collins \& Halverson, 2010; Garrett, 2009; Selwyn, 2003; Yang \& Chen, 2007). For instance, a number of institutions offer virtual self-access centres (VSACs), which are defined as 'an institutional website that facilitates independent language learning' (Gui \& Northern, 2013, p.1). These centres have the potential to supply 'resources for selfstudy, as well as, in some cases, forums or message boards to encourage interaction' with their fellows or tutors although they might experience an isolating and reclusive e-learning environment (ibid. p.1). Thereby, learners can be supported with the provision of OLR to take control of their learning not just in the classroom. However, they should also be assisted or scaffolded to pace their learning on their own. Scaffolding is considered 'the steps taken to reduce the degrees of freedom taken in carrying out some task so that the child [or learners more generally] can concentrate on the difficult skill she [or he] is in the process of acquiring' (Bruner, 1978 cited in Michell \& Sharpe, 2005, p.32, italics in original). When scaffolded within OLR, learners might need less scaffolding from their teacher but take responsibility for their learning. This leads to the 'ideal situation' for learning where learners tend to be more independent as less scaffolding is provided. However, the notion of the ideal situation depends on many variables in a learning setting. Therefore, designers should pay attention to those learners who gain learning in a new environment (Jarvis, 2012). Although the studies (i.e. Benson, 1998; Frizler, 1995; Reinders \& White, 2011; Warschauer, 1996, 2004) have found out that technology has the potential to increase learner autonomy, there has not been any in-depth study on learners' use, interaction and exercise of learner autonomy within OLR. In order to understand their learning with OLR in e-learning environments, this study is aimed to answer the following research questions:

1. What OLR do learners use to improve their academic English?

2. How do learners perceive their learning within OLR but without any human-based scaffolding?

3. How do learners exercise their autonomous learning when learning within OLR but without any humanbased scaffolding?

\section{Literature Review}

E-learning has been an essential focus in teaching and learning a language or languages because of the transmission of education and knowledge from traditional to new methods (Garrison, 2011). In a broad sense, Daly and Pachler (2010) define e-learning as:

'a set of practices which enhance the potential of people to learn with others via technology-aided interaction, in contexts which can be "free" of barriers of time and place. It involves the utilisation of a range of digital resources - visual, auditory and text-based - which enable learners to access, create and publish material which serves educational purposes. Essentially, this material can be shared electronically with fellow learners and teachers both within and beyond the bounds of formal education contexts' (p. 217).

On the one hand, Daly and Pachler (2010) show that e-learning is more than flexible learning and is related 
to what learners perform (Phillips, McNaught \& Kennedy, 2012). On the other hand, the definition is somewhat vague to discuss a learning environment supplied with e-learning. Therefore, this paper draws on the Joint Information Systems Committee (JISC, 2004), which exemplifies e-learning as any learning offered within laptops, computers, software, digital cameras, interactive whiteboards, virtual learning environments, wireless and mobile tools, learning activity management systems and electronic communication tools, such as video conferencing, discussion boards, email and chat facilities.

Studies have compared learning in traditional classrooms with technology-assisted learning (Hagel \& Shaw, 2006; Zhang, Zhao, Zhou \& Nunamaker, 2004). Table 1 summarises the drawbacks and benefits of each learning type.

Table 1: The Benefits and Drawbacks of Traditional Classroom Learning and E-learning (Zhang et al., 2004)

\begin{tabular}{lll}
\hline Benefits & Traditional Classroom Learning & E-learning \\
& Immediate feedback & Student-centred and self-paced \\
& $\begin{array}{l}\text { Familiarity with teaching and peers } \\
\text { Motivation }\end{array}$ & $\begin{array}{l}\text { Flexibility and accessibility } \\
\text { Cost-effectiveness }\end{array}$ \\
& $\begin{array}{l}\text { Development of a social } \\
\text { community }\end{array}$ & $\begin{array}{l}\text { Global delivery of education } \\
\text { Storage of information for reuse and sharing purposes }\end{array}$ \\
\hline Drawbacks & $\begin{array}{l}\text { Teacher-centred } \\
\text { Time and place restrictions }\end{array}$ & $\begin{array}{l}\text { Delayed feedback } \\
\text { Preparation time increasing for tutors } \\
\text { A more expensive cost of teaching } \\
\end{array}$ \\
& $\begin{array}{l}\text { Uncomfortable, frustrating and confusing for some } \\
\text { learners }\end{array}$ \\
\hline
\end{tabular}

The above table shows that not only technology itself, but also the tutors and designers have the potential to play an important role in the delivery of an effective instruction in e-learning environments. Above all, Shulman (1999) stresses that learning should be accessible and beyond the restricted environments, whereas Jacob (2013 cited in Hew, 2014) draws attention to a good resource which sets up 'the ultimate democratization of education' (p.1).

Considering the flexibility and accessibility of online learning resources, the potential of an effective elearning design has been in debate in the last decades rather than teaching restricted in the classroom environments. This shift from traditional learning to e-learning has led to the evolution of support or scaffolding provided to improve learning. Puntambekar and Hübscher (2005) draw attention to the change of the support provider who is an adult or expert in the traditional learning environments, whilst an authentic task in e-learning environments. Furthermore, scaffolder is represented with the knowledge of a person in the former, whereas as the assistance from tools and resources in the latter. Scaffolding is faded gradually in the former, while permanent and unchanging in the latter. The evolution of scaffolding triggers to discuss 'situations in which an individual is able to provide scaffolding for her(him)self when any problem or concept that is new to the individual is being tackled' (Holton \& Clarke, 2006, p.136). This notion yields the occurrence of self-scaffolding which the learner can provide for himself or herself.

Learning online through self-scaffolding or scaffolding from resources and tools is reported to be dependent on learner autonomy, which is commonly defined as the ability to take responsibility for one's own learning (Benson, 2001; Dickinson, 1987; Holec, 1981; Little, 1991). Linn (1996) and McLoughlin and Marshall (2000) highlight that the provision of scaffolding has the potential to promote learner autonomy. Toogood (2000) claims that learners will not improve their learning when given no support but just freedom or too much control, or when given too much control and too much support. She indicates that there should be a balance between freedom and support. Luzón (2006) shows a variety of ways to encourage learning in e-learning environments. Online learning resources or materials provided for users should increase learner awareness. Also, these resources or materials should help users evaluate their own learning by giving feedback. Considering the ways suggested by Luzón (2006), Ribbe and Bezanille (2013) summarise such features of an e-learning environment as 'learner reflection', 'learner involvement' and 'the immersion into the target community of practice' (p.102).

A number of researchers have looked at scaffolding and learner autonomy in an e-learning environment. Nielsen (2012) examines how online learning tools can promote learner autonomy for foreign language learning. Twenty-four international undergraduate students took an Arabic course for one year by using online learning tools such as individual plans, online tests, self-assessment and portfolio. The findings from the case studies about their use of the tools present that scaffolding from their teacher fostered their autonomous learning. This study indicates the support from a human but does not discuss the situations without any human support. However, Delen, Liew and Willson (2014) compare sixteen students in the control group with sixty-four students in the experimental group who received the additional features such as 'note-taking, supplemental resources, and practice questions' (p.134) in an online video learning environment. Data from the survey, a recall test and the frequency of their use show that the additional features increased the performance of the control group and played a crucial role as a scaffolder to activate self-regulated learning. The study by Delen et al. (2014) is good at the comparison between scaffolded and unscaffolded students. Moreover, Chen and Law (2016) investigate scaffolding in individual and 
collaborative game-based learning dividing two hundred fifty-four students into four groups: 'individual-control', 'individual-scaffold', 'collaborative-control', and 'collaborative-scaffold' (p.1201). The data obtained from an intrinsic motivation survey and a performance test present that 'scaffolding had an impact on students' motivation and learning performance' (Chen \& Law, 2016, p.1201). The study classifies scaffolding into hard scaffolding (i.e. static scaffolding from computers) and soft scaffolding (i.e. dynamic scaffolding from peers). It points out that both scaffolding types should be supplied in an e-learning environment.

In spite of the crucial studies on learners' use and perceptions of learning in online learning environments as listed above, there has been little research (Jarvis, 2012; Yelland \& Masters, 2007) and further studies have been needed to look at their learning deeply (Chen \& Law, 2016; Delen et al., 2014; Nielsen, 2012). Therefore, this paper shows and discusses an empirical study on how students perceive their learning and exercise learner autonomy when learning within OLR but without any human-based scaffolding.

\section{Research Methodology}

\subsection{Participants}

Thirty-five students (i.e. thirteen females and twenty-two males) coming from the Middle Eastern countries (i.e. twenty-four students) or Asian countries (i.e. eleven students) took part in this study voluntarily. They were aged between 21 and 45. They were studying English for academic purposes (EAP) at a UK university in order to undertake a postgraduate or undergraduate study in such various subjects as engineering, linguistics, geography or statistics in the following year. They took a compulsory module, Independent Study, which encouraged them to use the EAP Toolkit designed by the University, and other online learning resources that they could access in the University or at home. The participants were chosen because they were supported to use OLR independently, coming from different backgrounds and cultures and had the same aim to improve their academic English. Additionally, this study is interested in their use of OLR rather than the EAP Toolkit.

\subsection{Data Collection and Instruments}

This study consists of quantitative and qualitative research instruments. Pre-and post-questionnaires were conducted as a quantitative instrument in order to reduce the researcher's bias on data and increase the reliability and validity of findings (Dörnyei, 2003), whilst the interview was applied to look at participants' perceptions and experiences (Talmy, 2010). Both of data collection instruments were piloted as indicated by Meri-Yilan (2017), to increase the reliability and validity of the research. All of the participants filled out Online Learning Resources Rating Scale, which contains three Likert-scale statements and four closed or open-ended questions, and Learner Autonomy and Support Scale, which consists of six statements. In the former scale, they were asked to rate their use of OLR from not useful (scale=1) to very useful (scale=5), whereas in the latter, their supported autonomous learning from strongly disagree $(\mathrm{scale}=1)$ to strongly agree $($ scale $=5)$. Open-ended and closed questions asked what OLR they used, how often they used OLR, if they were supported within OLR, and if they wished to receive more scaffolding. A pre-questionnaire was distributed to them in February, whilst a post-questionnaire was done in May. Having been introduced about the study and distributed an information sheet, all of them signed the consent form and were ensured that their data were kept safely and anonymously. After each questionnaire, the researcher interviewed ten of them to have an in depth understanding of their beliefs when learning within OLR. Semi-structured interview questions were asked about those resources' helpfulness or otherwise and the students' recommendations for OLR's improvements.

\subsection{Data Analysis}

Quantitative data were analysed first by using statistical features with Statistical Package for the Social Sciences (SPSS) and then by interpreting the results (Bryman \& Cramen, 1990). Descriptive statistics such as percentages and frequencies of the variables, and inferential statistics such as McNemar's test were included to see a statistical change between questionnaires if any. Qualitative data were analysed by coding the transcripts of interview data in NVivo. The main codes were generated deductively (Miles and Huberman, 1994) such as the positive and negative views on the use of OLR, and other codes were created inductively (Hesse-Biber \& Leavy, 2011). Codes were discussed with two experts to ensure the validity of coded data (Freelon, 2010).

\section{Findings}

4.1 The Use of OLR

Table 2 indicates that not all of them used OLR in both questionnaire times, whereas there was a slight increase in the use of OLR over time. On the one hand, there is not statistically significant change in the numbers using OLR between the pre-and post-questionnaires, as shown in McNemar's test in Table 3. On the other hand, there was an increase in the frequency of the weekly use of OLRs over time even though there was a decrease in the frequency of the everyday use of OLRs over time. Twenty-one participants said that they used the resources every day in the pre-questionnaire, whereas eighteen of them stated that in the post-questionnaire. 
Table 2: Percentage and Frequency of the Participants' use of OLR in Pre- and Post-Questionnaires

\begin{tabular}{rllclc}
\hline & \multicolumn{2}{c}{ Pre-Questionnaire } & \multicolumn{2}{c}{ Post-Questionnaire } \\
& Frequency & Percentage & \multicolumn{2}{c}{ Frequency } & Percentage \\
\hline Yes & 31 & 88.6 & 33 & 94.3 \\
\hline No & 4 & 11.4 & 2 & 5.7 \\
\hline Total & 35 & 100.0 & 35 & 100.0 \\
\hline
\end{tabular}

Table 3: McNemar's Test for the Statistical Comparison of Use of OLR between Pre- and Post-Questionnaires Test Statistics ${ }^{\mathrm{a}}$

\begin{aligned} & \hline Pre-Questionnaire \& Post-Questionnaire \\ & N 35 \\ & Exact Sig. (2-tailed) $.625^{\mathrm{b}} \\ &$\hline\end{aligned}

\section{a. McNemar's test b. Binomial distribution used.}

Corroborating the quantitative data, the qualitative data from interviews show that the participants used a variety of OLR. Ten participants stated that they used at least four OLR during the interview. The most commonly used OLRs were TED.com, EngVid, YouTube, Using English for Academic Purposes (UEFAP), English town, English $4 \mathrm{u}$, the British Council and BBC resources, Word on the Street, Activities for ESL/EFL Students, Google and Google Scholar, apps on mobile phones, e-books, online newspapers and journals. They stated that they preferred to use these resources for content and vocabulary learning, to improve language skills, to look for academic papers and because of their reliability. However, the data do not show any difference in their use of OLR between the first and second interview times.

The quantitative data from the comparison between pre- and post-questionnaires present that the use of feedback increased over time. Sixteen of thirty-five participants said that they received feedback in the prequestionnaire, while twenty of them stated that in the post-questionnaire. Although four of them reported not to receive it from OLR, two of them said the same in the post-questionnaire.

\subsection{The Perceptions of Learning within OLR}

Data from ten participants' perceptions of their learning within OLR were categorised as positive and negative, while the comparison between pre- and post-questionnaires shows that their positive view slightly increased over time. Data from interviews show that they found the resources useful in that they received a number of e-books, practices and activities that support learners' listening, writing, speaking and reading skills and could evaluate their learning and concentrate on their learning at any time and place. Three of them stated that OLR encouraged their independent learning, and their motivation was risen by having fun and feeling satisfied. They also reported that the convenience and accessibility of OLR developed their flexible learning. One student exemplified that he could read and listen whenever and wherever he preferred, as e-books and audiobooks are easier to carry than printed books. Additionally, most of them reported that they could provide self-scaffolding by referring to another resource, when OLR did not offer any support.

However, they found them ineffective in offering academic teaching and intercultural content and providing enough scaffolding and collaboration and interaction with other people. Data from interviews show that nearly all of them preferred to receive feedback and scaffolding which add new information to their knowledge by explaining why they were wrong in the activities. Six of them exemplified such features of scaffolding as scripts, pronunciation, samples, instruction, explanations, a dictionary and additional practices of the activity. Three students reported that OLR should contain a discussion forum to provide interaction. One student stated that he overcame the lack of interaction in OLR by connecting with native speakers in English via social networking websites. Two of them drew attention to different accents and contents, with which they were unfamiliar culturally. However, one student found the problem in herself, as her age was too old to learn within OLR, as stated by her. Additionally, all of them indicated that they would have used OLR more if they had not been busy with classroombased homework, exams and projects.

\subsection{The Exercise of Learner Autonomy within OLR}

Data from the pre- and post-questionnaires indicate that there was a slight increase from thirty-two participants to thirty-three ones over time in that OLR could help them become a more independent learner. However, there was a slight decrease in that OLR supported them to explore new concepts in language learning (i.e. a decrease from thirty-two to twenty-nine participants), gave them a better opportunity to learn on their own (i.e. a decrease from thirty-four to thirty-two participants), gave them an opportunity to learn English independently with the support (i.e. a decrease from thirty-two to thirty-one participants) and made them aware of their own learning (i.e. a decrease from twenty-seven to twenty-six participants). Moreover, it remained stable that thirty-one participants thought that OLR helped them extend their language learning skills outside the classroom settings.

Consistent with quantitative data, data from interviews show that all of them believed that OLR promoted learner autonomy. Despite the effectiveness of OLR in language learning, participants reported that they needed 
their teacher's presence in e-learning settings. They also added that they would have worked more independently if they had received more or enough scaffolding and support. One student exemplified this as a kind of help to proceed into the activities.

\section{Discussion}

This study discusses three things happening in learning a language from the perspectives of learners of English for academic purposes. The first point is that EAP students use a variety of OLR to improve not just language skills but also academic skills. When learning within OLR, the second point is noted about the views on the resources to the extent that an e-learning environment should be designed according to learners' needs. Corroborating the research by Jarvis (2012), this study argues that learners should be adapted to a new learning environment. Related to the features of e-learning environments, the third point is arisen in that learners can increase learner autonomy with the help of technology. Although the previous studies have found out the potential effectiveness of technology for learner autonomy (Benson, 1998; Chen \& Law, 2016; Delen et al., 2014; Frizler, 1995; Nielsen, 2012; Reinders \& White, 2011; Warschauer, 1996, 2004), the present study further discusses to set up a useful e-learning environment.

Therefore, this paper considers the following components of a self-directed e-learning environment adapted from the study by Liaw, Huang and Chen (2007). Based on this study, learner autonomy, online learning resources and scaffolding from tools or humans, if applicable, have the potential to construct an effective learning environment.

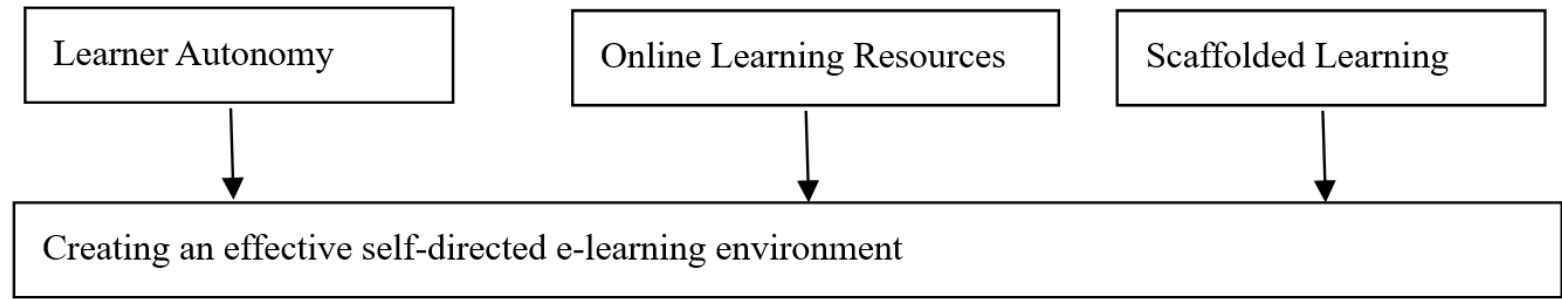

Figure 1: An Illustration of an Effective Self-directed E-learning Environment (adapted from Liaw et al., 2007)

Despite Liaw et al. (2007) noting the provision of scaffolding from tutors, this study highlights that scaffolding can be supplied from OLR when an effective self-directed e-learning environment is designed. As suggested by the participants in the current study, it lists the functions of scaffolding as giving a clear instruction and introduction about the questions, providing feedback not just for wrong responses but also right responses, explain the questions with the meanings of keywords and offering more related activities and practices. Consistent with the claims by Duffy and Azevedo (2015) and Veletsianos and Russell (2014), a well-provided and designed scaffolding resembles a teacher. Furthermore, this study draws attention to flexible learning (i.e. learning at any time and place) without any human-based help but scaffolding from the resources, and the unchanging and permanent scaffolding in e-learning environments.

\section{Conclusion}

The study contributes to the understanding of the EAP students' use of OLR in a UK university. It concludes that learners have the ability to look for a variety of OLR and integrate these resources into language learning not just for general purposes but also for academic purposes. OLR have the features to facilitate learners to improve language skills, especially through scaffolding. However, scaffolding should cover enough assistance for learners particularly in e-learning environments. Multiple scaffolders should be provided in that learners can receive enough information, introduction and explanation about the topic and feedback about the answers. As a scaffolder, self-scaffolding can play a major role in finding out the information in another resource or way. Therefore, this study recommends a well-designed e-learning environment. It makes suggestions for designers to consider the provision of enough scaffolding, teachers and institutions to integrate scaffolding into their teaching to promote learner autonomy, and students to utilize different OLR and enhance learner autonomy through scaffolding, including self-scaffolding in e-learning environments.

This paper reports a small-scale study. Longitudinal studies with a larger sample size can be carried out to look at students' use of different OLR and observe them when performing activities in order to see their behaviours rather than just their beliefs obtained through interviews. A further study can compare the control and experimental groups in an individualized and a collaborative e-learning environment. This study investigated the contexts of the Middle Eastern and Asian countries in a UK university. A further study should include other contexts and consider the similarities and differences between contexts.

\section{References}

Benson, P. (1998). The semiotics of self-access language learning in the digital age. In Darleguy, V., Ding, A., \& 
Svensson, M. (eds.). Educational Technology in Language Learning: Theoretical Considerations and Practical Applications. pp. 70-78. Lyon, France: INSA (National Institute of Applied Sciences).

Benson, P. (2001). Teaching and researching autonomy in language learning. (1st edn). Harlow: Pearson.

Bryman, A. \& Cramer, D. (1990). Quantitative Data Analysis for Social Scientists. London: Routledge.

Chen, C. H., \& Law, V. (2016). Scaffolding individual and collaborative game-based learning in learning performance and intrinsic motivation. Computers in Human Behavior, 55, 1201-1212.

Collins, A., \& Halverson, R. (2010). The second educational revolution: rethinking education in the age of technology. Journal of computer assisted learning, 26(1), 18-27.

Daly, C. and Pachler, N. (2010). E-Learning: the future? In J. Arthur \& I. Davies (Eds). Textbook on Educational Studies. Oxford: Routledge 216- 226.

Delen, E., Liew, J., \& Willson, V. (2014). Effects of interactivity and instructional scaffolding on learning: Selfregulation in online video-based environments. Computers \& Education, 78, 312-320.

Dickinson, L. (1987). Self-instruction in Language Learning. Cambridge: Cambridge University Press.

Dörnyei, Z. (2003). Questionnaires in Second Language Research: Construction, Administration, and Processing. Mahwah, NJ: Lawrence Erlbaum Associates.

Duffy, M. C., \& Azevedo, R. (2015). Motivation matters: Interactions between achievement goals and agent scaffolding for self-regulated learning within an intelligent tutoring system. Computers in Human Behavior, $52,338-348$.

Freelon, D. G. (2010). ReCal: Intercoder reliability calculation as a web service. International Journal of Internet Science, 5(1), 20-33.

Frizler, K. (1995). The Internet as an Educational Tool in ESOL Writing Instruction. Unpublished Master's thesis, San Francisco State University.

Garrett, N. (2009). Computer-Assisted Language Learning Trends and Issues Revisited: Integrating Innovation. The Modern Language Journal, 93(s1), 719-740.

Garrison, D. R. (2011). E-learning in the 21st century: A framework for research and practice (2nd edn). London: Routledge/ Taylor \& Francis.

Gui, D.A.F. \& Northern, A. (2013). Supplementing self-access learning for an English Language Centre through virtual platforms. Presented at the Experiential Learning in Virtual Worlds 2013 Conference in Lisbon, Portugal.

Hagel, P., \& Shaw, R. N. (2006). Students' perceptions of study modes. Distance Education, 27(3), $283-302$.

Hesse-Biber, S. N., \& Leavy, P. (2011). The practice of qualitative research. (2nd edition). London: SAGE.

Hew, K. F. (2014). Promoting engagement in online courses: What strategies can we learn from three highly rated MOOCS. British Journal of Educational Technology.

Holec, H. (1981). Autonomy in Foreign Language Learning. Oxford: Pergamon.

Holton, D., \& Clarke, D. (2006). Scaffolding and metacognition. International journal of mathematical education in science and technology, 37(2), 127-143.

Jarvis, H. (2012). Computers and learner autonomy: trends and issues. British Council ELT, 387.

JISC (Joint Information Systems Committee). (2004). Effective Practice with e-learning: A good practice guide in designing for learning.

Liaw, S. S., Huang, H. M., \& Chen, G. D. (2007). Surveying instructor and learner attitudes toward e-learning. Computers \& Education, 49(4), 1066-1080.

Linn, M.C. (1996). Cognition and distance learning. Journal of the American Society for Information Science, $47 / 11$, p. $827-842$

Little, D. (1991). Learner Autonomy. 1: Definitions, Issues and Problems. Dublin: Authentik.

Luzón, M. J. (2006). Providing scaffolding and feedback in online learning environments. Les Melanges CRAPEL $28 \mathrm{n}^{\circ}$ spécial: TIC et autonomie dans l'apprentissage des langues.

McLouglin, C. \& Marshall, L. (2000). Scaffolding: A model for learner support in an online teaching environment. In Herrman, A., \& Kulski, M.M. (eds). Flexible Futures in Tertiary Teaching. Proceedings of the 9th Annual Teaching and Learning Forum 2000. Perth, Curtin University of Technology.

Meri-Yilan, S. (2017). 'Take your Time' to 'Find yourself!': An Exploration of Scaffolded Autonomous ELearning Environments amongst International Students in a UK University. PhD Thesis. University of Southampton, Southampton, UK.

Michell, M., \& Sharpe, T. (2005). Collective instructional scaffolding in English as a second language classrooms. Prospect, 20(1).

Miles, M. \& Huberman, M. (1994) Qualitative Data Analysis. London: Sage.

Nielsen, H.L. (2012). E-learning and the Dilemma of Learner Autonomy: A Case Study of First Year University Students of Arabic, Orientalia Suecana, Vol. LXI, No. Suppl, 2012, p. 89-106.

Phillips, R., McNaught, C., \& Kennedy, G. (2012) Evaluating E-Learning: Guiding Research and Practice. London: Routledge. 
Puntambekar, S., \& Hübscher, R. (2005). Tools for scaffolding students in a complex learning environment: What have we gained and what have we missed? Educational psychologist, 40(1), 1-12.

Reinders, H., \& White, C. (2011). Special issue commentary: Learner autonomy and new learning environments. Language Learning and Technology, 15(3), 1-3.

Ribbe, E., \& Bezanilla, M. J. (2013). Scaffolding learner autonomy in online university courses. Digital Education Review, (24), 98-112.

Selwyn, N. (2003). Why students do (and do not) make use of ICT in university. Paper presented to the 'Finding Common Ground: IT Education, Dearing and Democracy in the Information Society' Conference University of Leeds Department of Computing - July 9th 2003.

Shulman, L. (1999). Taking Learning Seriously. Change Magazine, 31 (4).

Talmy, S. (2010). Qualitative interviews in applied linguistics: From research instrument to social practice. Annual Review of Applied Linguistics, 30, 128-148.

Veletsianos, G., \& Russell, G. S. (2014). Pedagogical agents. In Handbook of research on educational communications and technology (pp. 759-769). Springer New York.

Warschauer, M. (1996). Computer-assisted language learning: An introduction. In FOTOS, Sandra (ed). Multimedia Language Teaching. Tokyo: Logos International, p. 3-20.

Warschauer, M. (2004). Technological change and the future of CALL. In S. Fotos \& C. Brown (Eds.), New Perspectives on CALL for Second and Foreign Language Classrooms (pp. 15-25).

Yang, S. C., \& Chen, Y. J. (2007). Technology-enhanced language learning: A case study. Computers in Human Behavior, 23(1), 860-879.

Yelland, N. \& Masters, J. (2007). Rethinking scaffolding in the information age. Computers \& Education, 48(3), 362-382.

Zhang, D., Zhao, J. L., Zhou, L., \& Nunamaker Jr, J. F. (2004). Can e-learning replace classroom learning? Communications of the ACM, 47(5), 75-79. 